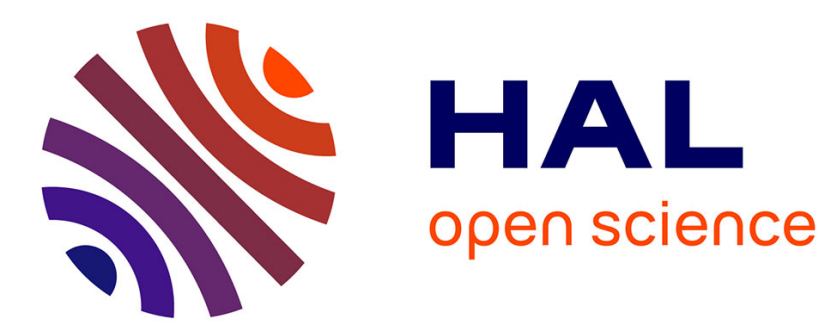

\title{
An equation of state for xenon/krypton mixtures confined in the nuclear fuels
}

Andrei Jelea

\section{To cite this version:}

Andrei Jelea. An equation of state for xenon/krypton mixtures confined in the nuclear fuels. Journal of Nuclear Materials, 2020, 530, pp.151952. 10.1016/j.jnucmat.2019.151952 . hal-02454919

\section{HAL Id: hal-02454919 \\ https://hal.science/hal-02454919}

Submitted on 24 Jan 2020

HAL is a multi-disciplinary open access archive for the deposit and dissemination of scientific research documents, whether they are published or not. The documents may come from teaching and research institutions in France or abroad, or from public or private research centers.
L'archive ouverte pluridisciplinaire HAL, est destinée au dépôt et à la diffusion de documents scientifiques de niveau recherche, publiés ou non, émanant des établissements d'enseignement et de recherche français ou étrangers, des laboratoires publics ou privés.

\section{(1) (1) $\$$}

Distributed under a Creative Commons Attribution - NonCommercial - NoDerivatives 44.0 


\title{
An equation of state for xenon/krypton mixtures confined in the nuclear fuels
}

\author{
A. Jelea ${ }^{*}$ \\ Institut de Radioprotection et de Sûreté Nucléaire (IRSN), PSN/SEMIA/LPTM, BP3, 13115 \\ Saint-Paul-lez-Durance, France
}

\begin{abstract}
In the present paper, one proposes an equation of state allowing to reasonably describe the behavior of the xenon/krypton mixtures, in any proportion, confined in the form of nanoscale bubbles in the $\mathrm{UO}_{2}$ and $\mathrm{MOX}$ nuclear fuels. The temperature range covered by this equation lies between the room temperature and the fuel melting point. The equation of state, which was built based on molecular dynamics results obtained on a large density-compositiontemperature range, could be easily implemented in the nuclear fuel performance codes.
\end{abstract}

Keywords: noble gases, nuclear fuel, molecular dynamics, equation of state

\footnotetext{
* Corresponding author at: Institut de Radioprotection et de Sûreté Nucléaire (IRSN), PSN/SEMIA/LPTM, BP3, 13115 Saint-Paul-lez-Durance, France

E-mail address: andrei.jelea@irsn.fr (A. Jelea)
} 


\section{Introduction}

Uranium dioxide $\left(\mathrm{UO}_{2}\right)$ or its mixtures (MOX fuels) with plutonium dioxide $\left(\mathrm{PuO}_{2}\right)$ are used as nuclear fuels in fission reactors. Noble gas species, such as xenon (Xe) and krypton $(\mathrm{Kr})$, form as fission reaction products at the rate of about $0.25-0.30$ atoms per fission event. $\mathrm{Xe}$ is seven times more frequently produced than $\mathrm{Kr}$ [1]. These noble gases have a very low solubility in the fuel matrix and, consequently, they precipitate together into the fuel under the form of intragranular and intergranular bubbles [1]. In low burnup fuels, the intragranular bubbles are typically less than $10 \mathrm{~nm}$ in diameter [2-4] while in high burnup fuels, some of these small bubbles can coalesce to lead to a bimodal bubbles population, with the largest bubbles of tens [2,3] or even hundreds [5] of nanometers in diameter. The intergranular bubbles are generally larger in size than the intragranular ones, with a diameter of several hundreds of nanometers $[5,6]$. The noble gas density in the intragranular bubbles ranges from about $10 \mathrm{~nm}^{-3}$ to slightly more than $30 \mathrm{~nm}^{-3}[3,7,8]$ while for the intergranular bubbles, the estimated densities are less than $10 \mathrm{~nm}^{-3}$ [6]. The molar fraction of $\mathrm{Kr}$ in the $\mathrm{Xe} / \mathrm{Kr}$ noble gas mixture in the bubble, of $0.12-0.14[2,6]$, mirrors the production rates of the two noble gases.

The bubble formation into the fuel alters its overall thermomechanical properties through modifying its microstructure, and, in addition, it can also lead to fuel swelling. These changes can have an impact on fission gas release to the fuel rod free volume and result in enhanced cladding stresses. All these effects of the bubble presence in the fuel, generally viewed as performance limiting factors during the normal functioning of the reactor, could have dramatic consequences for the safety of nuclear devices in accident conditions. This is the reason why modeling the evolution of the fission gas bubbles in nuclear fuels under irradiation is a crucial step in any kind of simulation of nuclear fuel rod behavior in accident conditions. 
The growth rate equations allowing to model the fission gas bubble evolution in nuclear fuels [9] make use of equations of state (EOS) in order to characterize the behavior of the noble gases confined in bubbles. To our knowledge, none of these EOSs is designed to describe mixtures of $\mathrm{Xe}$ and $\mathrm{Kr}$ or to take into account a possible bubble confinement effect. Moreover, as shown in Fig.1, some of the most popular EOSs [10-12] predict pressure-density curves that deviate significantly from the experimental data [13], or even display an unphysical behavior (the van der Waals and Kaplun EOSs), for densities higher than $10 \mathrm{~nm}^{-3}$. The implication of this is that the currently used EOSs cannot satisfactorily characterize the high density noble gases confined in the intragranular bubbles.

The present work aims at building an EOS of a simple form allowing to describe the behavior of $\mathrm{Xe} / \mathrm{Kr}$ mixtures of any composition confined under the form of bubbles in the $\mathrm{UO}_{2} / \mathrm{PuO}_{2}$ nuclear fuels at densities in agreement with experimental observations (from below $10 \mathrm{~nm}^{-3}$ to above $30 \mathrm{~nm}^{-3}$ ) and for temperatures lying between the room temperature and the nuclear fuel melting point. This equation is built using molecular dynamics (MD) generated data following two steps: in the first step, one determines the parameters of the EOS corresponding to the unconfined noble gas mixture and in the second step, one analyses the impact of the confinement on the noble gas behavior in the bubble. This analysis is necessary, because an earlier study [14] suggested the existence of a confinement effect in the case of Xe bubbles in $\mathrm{UO}_{2}$.

The paper is structured as follows: Section 2 presents the technical details of the MD simulations carried out in the present study. In Section 3 are discussed the steps taken to build the EOS for $\mathrm{Xe} / \mathrm{Kr}$ noble gas mixtures in bubbles. Section 4 gives a summary of the results of this study. 


\section{Methodology}

\subsection{Calculation details}

MD simulations in a NPT (constant Number of particles, Pressure and Temperature) ensemble $[15,16]$ employing $3 \mathrm{D}$ periodic boundary conditions were performed using the LAMMPS code [17]. The temperature and pressure were controlled using the Nose-Hoover thermostat and barostat [16] with the coupling parameters of $0.02 \mathrm{ps}$ and $0.2 \mathrm{ps}$, respectively. A timestep of $0.2 \mathrm{fs}$ was employed in the MD integration.

When simulating the unconfined noble gases, one used a two-phase solid/fluid supercell containing a mixture of $1728 \mathrm{Xe}$ and $\mathrm{Kr}$ atoms in different proportions, the composition being constant throughout the supercell. This solid/fluid system was built starting from two $6 \times 6 \times 6$ fcc supercells containing 864 noble gas atoms each. One of these supercells was relaxed at a relatively low pressure $(0.1 \mathrm{GPa})$ and high temperature $(3300 \mathrm{~K})$ in order to transform it into a fluid structure. The solid ( $\mathrm{fcc}$ ) and fluid structures were then adjusted to have the same density and put together to form the two-phase simulation cell. Multiphase systems of this type proved to be very appropriate for building phase diagrams $[18,19]$. Each MD simulation of these systems comprised $400 \mathrm{ps}$ for equilibration and $200 \mathrm{ps}$ for production. The instantaneous and average values of the property of interest, the noble gas density, were then calculated from the instantaneous volumes $\left(10^{4}\right.$ values $)$ recorded during the production part of the run.

The model representing the confined noble gases (bubble/matrix system) was built starting from a supercell of $7 \times 7 \times 7 \mathrm{MO}_{2}(\mathrm{M}=\mathrm{U}, \mathrm{Pu})$ fluorite elementary cells. Spherical cavities with $R_{C}$ radii in the nanometer range $(0.7 \mathrm{~nm}$ and $1.2 \mathrm{~nm})$ were carved by removing a stoichiometric number of actinide and oxygen atoms in the middle of this supercell. Different 
numbers of $\mathrm{Xe}$ or $\mathrm{Kr}$ atoms were then randomly placed into the cavities so as to cover a range of noble gas densities in the bubble, from below $10 \mathrm{~nm}^{-3}$ to above $30 \mathrm{~nm}^{-3}$, in agreement with the experimental findings (see Section 1). These bubble/matrix systems were equilibrated during 60 ps then the results were accumulated over 40 ps. $3.5 \times 10^{4}$ sets of instantaneous values of atomic coordinates and stress tensor components recorded during the production run were subsequently used to compute the instantaneous and average values of the properties of interest: noble gas pressures and densities in the bubble and bubble radii.

The pressure in the bubble was computed using the atomic stress tensor diagonal components (provided by LAMMPS in pressure $\times$ volume units [17]) of the noble gas atoms contained in the bubble and the bubble volume. The bubble volume was that of a sphere with the radius $\left(R_{B}\right)$ being calculated as the arithmetic mean between a "cavity minimum radius" and a "cluster maximum radius". The "cavity minimum radius" was defined as the distance between the bubble mass center and the closest matrix atom (actinide or oxygen) and the "cluster maximum radius" as the distance between the bubble mass center and the furthest atom (Xe or $\mathrm{Kr}$ ) in the noble gas cluster [14].

\subsection{Interatomic potentials}

All calculations were performed using semi empirical interatomic potentials to describe the three types of interactions that are present in the systems: the in-matrix M-M, M-O and OO interactions $(\mathrm{M}=\mathrm{U}, \mathrm{Pu})$, the gas-matrix $\mathrm{M}-\mathrm{G}$ and $\mathrm{O}-\mathrm{G}$ interactions $(\mathrm{G}=\mathrm{Xe}, \mathrm{Kr})$ and the gas-gas G-G interactions.

For the in-matrix interactions, one used the embedded atom method (EAM) type potentials of Cooper et al. [20] with the revised $\mathrm{PuO}_{2}$ potential parameters [21]. The Cooper potentials 
allow to reproduce very well, for $\mathrm{UO}_{2}$ and $\mathrm{PuO}_{2}$, the available experimental data relative to the stability of the fluorite phase, the variation of the lattice parameter with temperature, the elastic constants, the variation of the bulk modulus with temperature, the melting points, the superionic transition temperatures, the change in enthalpy relative to $300 \mathrm{~K}$ as a function of temperature and the variation of the specific heat with temperature [20,21]. Moreover, these potentials provide reasonable values, with respect to Density Functional Theory (DFT) results, for the formation energies of the Schottky and Frenkel defects in $\mathrm{UO}_{2}$ [20].

The gas-matrix interactions were described by employing the pair potentials proposed by Cooper et al. in reference [22]. These potentials have a Buckingham-Hill form and their parameters were adjusted to reproduce the gas-matrix forces predicted by DFT. The trapping energies for the incorporation of $\mathrm{Xe}$ and $\mathrm{Kr}$ atoms into an oxygen vacancy, actinide vacancy and Schottky defect calculated with these potentials agree well with DFT results. The best agreement with DFT data is reached for the trapping energy into the most stable trapping site, the Schottky defect. The gas-matrix Cooper potentials generally perform better than other gasmatrix semi empirical potentials from the literature, including the popular Grimes and Catlow ones [22].

In order to avoid the non-physical singularity at zero-distance, which is a feature of the Buckingham-Hill functions, in the present work, the gas-matrix Cooper pair potentials were used with a slight modification: for small atom-atom distances, one replaced the BuckinghamHill functions with Born-Mayer ones. The gas-matrix potentials thus modified have the following form: 


$$
V_{a b}\left(r_{i j}\right)=\left\{\begin{array}{cc}
B_{a b} \exp \left(-\frac{r_{i j}}{D_{a b}}\right) & r_{i j} \leq r_{c u t} \\
A_{a b} \exp \left(-\frac{r_{i j}}{\rho_{a b}}\right)-\frac{C_{a b}}{r_{i j}^{6}} & r_{i j}>r_{c u t}
\end{array}\right.
$$

In equation (1), $r_{i j}$ is the distance between atoms $i$ and $j, a$ and $b$ indicate the species of atom $i$ and atom $j$ respectively and $r_{c u t}$ is the inflection point of the Buckingham-Hill function situated between $r_{i j}=0$ and the equilibrium distance $r_{i j}=r_{m i n}$. The parameters of the BornMayer functions, $B_{a b}$ and $D_{a b}$, which were calculated from the conditions of continuity and derivability of the potentials in $r_{c u t}$, together with the corresponding $r_{c u t}$ values, are shown in Table 1. The parameters of the Buckingham-Hill functions, $A_{a b}, \rho_{a b}$ and $C_{a b}$, are those given by Cooper et al. [22].

In reference [23], Ross et al. proposed to describe the interaction between the noble gas atoms using exp-6 functions:

$$
V_{a b}\left(r_{i j}\right)=\varepsilon_{a b}\left\{\left(\frac{6}{\alpha_{a b}-6}\right) \exp \left[\alpha_{a b}\left(1-\frac{r_{i j}}{r_{a b}^{*}}\right)\right]-\left(\frac{\alpha_{a b}}{\alpha_{a b}-6}\right)\left(\frac{r_{a b}^{*}}{r_{i j}}\right)^{6}\right\}
$$

where $r_{i j}, i, j, a$ and $b$ have the same meaning as in equation (1). The parameters of these functions can be determined from the corresponding states theory, using as reference the parameters of the extensively tested argon-argon (Ar-Ar) potential. Thus, the Ar parameters $\varepsilon_{A r A r}$ and $r_{A r A r}^{*}$ may be scaled to those of another noble gas, $\varepsilon_{a a}$ and $r_{a a}^{*}$, by taking ratios of the critical temperatures $T_{c}$ and volumes $V_{c}$ : 


$$
\begin{gathered}
\frac{\varepsilon_{a a}}{\varepsilon_{A r A r}}=\frac{T_{c}^{a}}{T_{c}^{A r}} \\
\text { and } \\
\frac{r_{a a}^{*}}{r_{A r A r}^{*}}=\sqrt[3]{\frac{V_{c}^{a}}{V_{c}^{A r}}}
\end{gathered}
$$

Ross et al. [23] determined using this method the parameters of the Xe-Xe potential, $\varepsilon_{X e X e}$ and $r_{X e X e}^{*}$. The parameter $\alpha_{X e X e}$ kept the same value as for the Ar-Ar potential $\left(\alpha_{X e X e}=\alpha_{A r A r}=\right.$ 13). The Xe-Xe potential was then successfully employed $[18,19,24]$ to describe the Xe properties at high pressures and temperatures (equations of state, phase diagrams). Given the success of the Xe-Xe potential, one employed the Ross method to also determine the parameters of the $\mathrm{Kr}-\mathrm{Kr}$ potential. For this purpose, one used the following values: $\varepsilon_{A r A r}=122$ $\mathrm{K}, r_{A r A r}^{*}=3.85 \AA, T_{c}^{A r}=150.9 \mathrm{~K}, V_{c}^{A r}=75 \mathrm{~cm}^{3} / \mathrm{mol}, T_{c}^{K r}=209.4 \mathrm{~K}$ and $V_{c}^{K r}=91 \mathrm{~cm}^{3} / \mathrm{mol}$. In the same manner as in the case of Xe [23], one took $\alpha_{K r K r}=\alpha_{A r A r}=13$.

The parameters of the exp-6 potential describing the $\mathrm{Xe}-\mathrm{Kr}$ heterogeneous interactions were then calculated from the parameters of the homogeneous $\mathrm{Xe}-\mathrm{Xe}$ and $\mathrm{Kr}-\mathrm{Kr}$ interactions using the combination rules proposed by Kong and Chakrabarty [25]. The values of the parameters $\varepsilon_{a b}, r_{a b}^{*}$ and $\alpha_{a b}(a, b=\mathrm{Xe}, \mathrm{Kr})$ are given in Table 2

In the short distance regions of the gas-gas potentials, Born-Mayer functions were employed in the same manner and for the same reasons as in the case of the gas-matrix potentials. The parameters of the gas-gas Born-Mayer functions can be found in Table 1 .

The gas-gas Ross potentials were assessed by comparing the $P(\rho)$ curves calculated using these potentials (through NPT-MD simulations on two-phase supercells as described at Section 2.1) with experimental pressure-density $(P-\rho)$ data points $[13,26-28]$ at low and high 
densities/pressures and with the curves predicted by two recently derived $\mathrm{Xe}-\mathrm{Xe}$ and $\mathrm{Kr}-\mathrm{Kr}$ potentials $[29,30]$. These recent potentials were built by fitting to very accurate ab initio interaction energies at the complete basis set limit obtained using the post-Hartree-Fock coupled-cluster method with single, double, triple and quadruple excitations in conjunction with very large basis sets. Core-core and core-valence correlation and relativistic effects were also taken into account in these ab initio calculations.

At low densities/pressures, in the case of $\mathrm{Xe}$, the $P(\rho)$ curves calculated using the ab initio derived potential are in a better agreement with the experimental results than those predicted by the Ross potential (Fig. 2). However, the results of the Ross potential are still reasonable and they improve with increasing density and temperature. In the case of $\mathrm{Kr}$, both potentials predict low-density $P(\rho)$ curves in very good agreement with experimental data (Fig. 3)

At high densities/pressures, for both $\mathrm{Xe}$ and $\mathrm{Kr}$, the $P(\rho)$ curves calculated using the Ross potentials are in very good agreement with the experimental results while those predicted by the ab initio derived potentials deviate from the experimental points with increasing density (Fig.4)

The $a b$ initio derived potentials were built using interaction energies which were calculated for isolated pairs of atoms. Therefore, as there is no perturbation induced by an atomic environment on the interaction between any two atoms, these potentials do not take into account the many-body effects. For this reason, at high densities/pressures, where the atoms are very close to each other and the many-body effects become significant, they fail to predict $P(\rho)$ curves in agreement with experimental data. Meanwhile, at low densities/pressures, where the many-body effects are negligible, the predictions of the ab initio derived potentials are accurate. On the other side, given that the parameters of the Ross potentials were obtained from high-density noble gas experimental data (critical temperature 
and critical volume), these potentials incorporate some many-body features in the sense that they describe two-body interactions which are perturbed in an effective manner by an atomic environment. This explains why, at high densities/pressures, the predictions of the Ross potentials are in a better agreement with the experiment than those of the ab initio derived ones.

Because the Ross potentials are generally capable of predicting pressure-density curves in very good agreement with the experiment at both low and high densities, one used them in the subsequent calculations

As two of our approaches could have an impact on the simulation results, one carried out calculations in order to quantify this impact.

Firstly, one checked that the introduction of a Born-Mayer function at small atom-atom separations does not significantly alter the initial prediction capacity of the gas-matrix Cooper potentials. This was carried out by comparing (see Table 3) the trapping energies for Xe and $\mathrm{Kr}$ at different sites of a $7 \times 7 \times 7 \quad \mathrm{UO}_{2}$ or $\mathrm{PuO}_{2}$ supercell determined through energy minimisation calculations using our trio of potentials (Cooper/Cooper/Ross) and the corresponding values extracted from Fig. 4 of reference [22]

In the end, one verified that our $7 \times 7 \times 7$ supercell (supercell length of about $3.83 \mathrm{~nm}$ ) is large enough to minimize the bubbles interactions with their periodic images by evaluating the impact of the supercell size on the bubble radius and the noble gas density and pressure in the bubble. To this end, one performed NPT-MD simulations at $1400 \mathrm{~K}$, using the Cooper/Cooper/Ross set of potentials, on four types of systems $\left(\mathrm{Xe} / \mathrm{UO}_{2}, \mathrm{Xe} / \mathrm{PuO}_{2}, \mathrm{Kr} / \mathrm{UO}_{2}\right.$ and $\left.\mathrm{Kr} / \mathrm{PuO}_{2}\right)$ where the largest bubbles analyzed in the present study $\left(R_{B} \approx 1.2 \mathrm{~nm}\right)$ with high noble gas densities (from 24 to $26 \mathrm{~nm}^{-3}$ ) were placed in a $7 \times 7 \times 7$ supercell and in a larger 
$9 \times 9 \times 9$ supercell (supercell length of about $4.92 \mathrm{~nm}$ ). As shown in Table 4, the bubble properties corresponding to the two supercell sizes are very similar. One should add that in our $7 \times 7 \times 7$ supercells, even for the largest bubbles, the bubble separation between the periodic images (about $1.43 \mathrm{~nm}$ ) surpasses the cutoff distance $(1 \mathrm{~nm})$ of the gas-gas potentials. This allows avoiding the direct interactions between the noble gas atoms and their periodic images and as a consequence, there is no impact of the supercell size on the noble gas behavior in the bubble. 


\section{Results and discussion}

\subsection{The analytical form of the EOS}

An EOS of a simple form that allows describing the behavior of a pure fluid confined in the form of bubbles in a solid matrix was introduced in a previous paper [31] dedicated to the study of helium bubbles in steel matrices. This EOS can be adapted to describe the $\mathrm{Xe} / \mathrm{Kr}$ mixtures confined in actinide oxides matrices, thus taking the following form:

$$
P_{B}\left(\rho_{B}, x, T, R_{B}\right)=\rho_{B} C\left(R_{B}\right) k T+\sum_{i=1}^{3} F_{i}(x, T) \rho_{B}^{i+1} C^{i+1}\left(R_{B}\right)
$$

In equation (4), $P_{B}$ and $\rho_{B}$ are the pressure and the density respectively of the noble gases in the bubble, $R_{B}$ is the bubble radius, $k$ is the Boltzmann's constant and $F_{l}(x, T)$ are functions of the composition $x$ (the molar fraction of $\mathrm{Kr}$ ) of the $\mathrm{Xe} / \mathrm{Kr}$ mixture and temperature $T$. A second degree polynomial function can be employed to describe the dependence of $F_{i}(i=1$, 2, 3) on composition $x$ :

$$
F_{i}(x, T)=A_{i}(T) x^{2}+B_{i}(T) x+C_{i}(T)
$$

The temperature dependent coefficients of equation (5), $A_{i}(T), B_{i}(T)$ and $C_{i}(T)$, can also be expressed as second degree polynomial functions with the adjustable parameters $A_{i j}, B_{i j}$ and $C_{l j}(i, j=1,2,3)$

$$
\begin{aligned}
& A_{i}(T)=A_{i 1} T^{2}+A_{i 2} T+A_{i 3} \\
& B_{i}(T)=B_{i 1} T^{2}+B_{i 2} T+B_{i 3} \\
& C_{i}(T)=C_{i 1} T^{2}+C_{i 2} T+C_{i 3}
\end{aligned}
$$


Finally, the term $C\left(R_{B}\right)$ from equation (4) allows taking into account the matrix confinement effect on the noble gases through the use of an effective global parameter $\Delta R$ :

$$
C\left(R_{B}\right)=\frac{R_{B}^{3}}{\left(R_{B}-\Delta R\right)^{3}}
$$

In the case of unconfined (free) noble gases ( $\Delta R=0 \AA$ ), equation (4) becomes:

$$
P_{F}\left(\rho_{F}, x, T\right)=\rho_{F} k T+\sum_{i=1}^{3} F_{i}(x, T) \rho_{F}^{i+1}
$$

where $P_{F}$ and $\rho_{F}$ denote the free noble gas pressure and density respectively.

The following two sections present the steps taken to determine the parameters $A_{i j}, B_{i j}, C_{i j}$ and $\Delta R$ of the previously introduced EOS.

\subsection{The parameters $A_{i j}, B_{i j}$ and $C_{i j}$}

The values of the EOS parameters $A_{i j}, B_{i j}$ and $C_{i j}$ (Table 5) were determined with the method of least squares (as implemented in the Igor Pro software) by fitting equation (8) to a set of pressure-density-composition-temperature $(P-\rho-x-T) \mathrm{MD}$ data points corresponding to unconfined $\mathrm{Xe} / \mathrm{Kr}$ mixtures. The $\mathrm{MD}$ data points were obtained through simulations in the NPT ensemble on two-phase supercells in the manner described at Section 2.1. The MD calculations were carried out at seven different temperatures from $300 \mathrm{~K}$ to $3300 \mathrm{~K}$ and over the pressure range from $0.1 \mathrm{GPa}$ to $19 \mathrm{GPa}$. The proportion of the $\mathrm{Xe}$ and $\mathrm{Kr}$ atoms in the simulation box was varied as to give multiple compositions: $x=0$ (pure $\mathrm{Xe}$ ), $x=0.25, x=0.5$, $x=0.75$ and $x=1$ (pure $\mathrm{Kr})$. 
In the $T-P$ range covered by our MD simulations, the noble gases behave either as supercritical fluids or solids. As exemplified on Fig. 5 for pure Xe and pure Kr, at relatively low temperatures, the present MD calculations found fluid-to-solid phase transitions, in agreement with experimental findings [32] or other simulation results $[18,19]$. The discontinuities associated with the fluid-to-solid phase transitions are barely noticeable, allowing us to neglect them in the fitting process without significantly altering the quality of the resulting fit.

Given that one used an fcc structure for the solid phase of the initial two-phase solid/fluid supercells, the MD simulations predicted only an fcc crystalline structure for the final monophase solid systems. Some experimental studies [33] showed that, in the case of Xe and $\mathrm{Kr}$, fcc and hcp solid phases could coexist (at least at room temperature) on a quite large range of pressures. However, given that the fcc and hcp solid phases have the same molar volume [33], the inability of our MD simulations to reproduce the coexistence of the two solid phases is not expected to have any impact on the MD calculated $P-\rho$ data points.

As shown on Fig. 6, equation (8) encapsulates fairly accurately the totality of the MD data used in the fitting process. It has to be mentioned, that this equation, despite its formal resemblance to a virial expansion up to the fourth coefficient, cannot be considered as such. Indeed, a fourth-order virial equation can be properly employed to describe fluids, but if forced to fit $P-\rho$ data points in both fluid and solid domains, as is the case with equation (8), it loses the physical meaning of its virial coefficients. Moreover, the functional form one chose to describe the dependence of the $F_{2}$ and $F_{3}$ terms of equation (8) on composition does not correspond to that of a virial equation [34] 


\subsection{The confinement parameter $\Delta R$}

The confinement parameter was determined by selecting the value of $\Delta R$ which minimizes a penalty function $S(\Delta R)$ defined as a sum of squared residuals:

$$
S(\Delta R)=\frac{1}{N_{P}} \sum_{j=1}^{N_{P}}\left[P_{B, j}^{E O S}(\Delta R)-P_{B, j}^{M D}\right]^{2}
$$

$P_{B, j}^{E O S}(\Delta R)$ is the pressure in the bubble calculated for a given $\left(\rho_{B}, x, T, R_{B}\right)$ set of values using equations (4)-(7) with the previously determined parameters $A_{i j}, B_{i j}$ and $C_{i j}, P_{B, j}{ }^{M D}$ is the corresponding pressure in the bubble calculated by MD simulations and $N_{P}$ represents the number of MD values used in the fitting process

The MD data points were obtained using the methods and the bubble/matrix systems built as presented in Section 2.1. Four types of bubble/matrix systems were created, $\mathrm{Xe} / \mathrm{UO}_{2}$, $\mathrm{Kr} / \mathrm{UO}_{2}, \mathrm{Xe} / \mathrm{PuO}_{2}$ and $\mathrm{Kr} / \mathrm{PuO}_{2}$, which correspond to the lower and the upper limits for the composition of the $\mathrm{Xe} / \mathrm{Kr}$ mixture in the bubble or the $\mathrm{UO}_{2} / \mathrm{PuO}_{2}$ mixture in the solid matrix. The MD calculations were carried out at temperatures of $500 \mathrm{~K}, 1400 \mathrm{~K}$ and $2300 \mathrm{~K}$, thus covering a large temperature range. No external pressure was applied to the simulated systems $(P=0 \mathrm{GPa})$

For the four types of bubble/matrix systems considered here, the following $\Delta R$ values were obtained by fitting: $-0.003 \AA$ ( $\mathrm{Xe} / \mathrm{UO}_{2}$ systems), $0.022 \AA\left(\mathrm{Kr} / \mathrm{UO}_{2}\right.$ systems), $-0.01 \AA$ $\left(\mathrm{Xe} / \mathrm{PuO}_{2}\right.$ systems $)$ and $0.013 \AA\left(\mathrm{Kr} / \mathrm{PuO}_{2}\right.$ systems $)$. Whatever the case, the $\Delta R$ values are very low suggesting a negligible confinement effect. Actually, as shown on Fig.7, the EOS encapsulates in a reasonable manner all the MD data for pure confined $\mathrm{Xe}$ or $\mathrm{Kr}$ used in the fitting process, regardless of whether or not the confinement was taken into account. 
Therefore, the confined noble gases could be correctly described using the EOS corresponding to the unconfined ones $(\Delta R=0 \AA)$.

In order to strengthen this last conclusion, one also included in Fig.7 a comparison between the pressures in the bubble at $1800 \mathrm{~K}$ calculated using our EOS with $\triangle R=0 \AA$ and the corresponding MD values for eight systems obtained by filling 0.7 and $1.2 \mathrm{~nm}$ radius cavities in $\mathrm{UO}_{2}$ and $\mathrm{PuO}_{2}$ with $\mathrm{Xe} / \mathrm{Kr}$ mixtures of two different compositions $(x=0.33$ and $0.66)$.

A previous $\mathrm{MD}$ study [14] found that, for Xe nanobubbles in $\mathrm{UO}_{2}$, the pressure of the confined noble gas was higher than its bulk pressure at an equivalent density and temperature. This result indicates a confinement effect, in the sense that the $\mathrm{UO}_{2}$ matrix induces a more repulsive environment for the cluster of Xe atoms in the bubble than the environment this cluster of atoms would have in the bulk at the same density and temperature. These findings are in contradiction with those of the present study. The magnitude of the confinement effect is dependent on the ratio between the gas-matrix and the gas-gas interactions, since most, if not all, of the noble gas atoms in small bubbles interact both with the matrix atoms and with similar noble gas atoms. As shown on Fig. 8, the potentials used in reference [14] describe Xe-matrix interactions that are more repulsive and Xe-Xe interactions that are less repulsive than the corresponding ones from the present study. This helps to explain why in reference [14] the matrix environment was found to be more repulsive for the confined Xe atoms than suggested by the present results. However, the good accuracy of the potentials used in this work (see Section 2.2) provides a higher level of confidence in the present results, showing a negligible confinement effect. 


\section{Conclusions}

In the present work, an EOS (equations (4)-(7)) was built that allows describing $\mathrm{Xe} / \mathrm{Kr}$ mixtures, in any proportion, confined in the form of bubbles in the nuclear fuels like $\mathrm{UO}_{2}$ and MOX. This equation is valid for a noble gas density range in the bubble from below $10 \mathrm{~nm}^{-3}$ to above $30 \mathrm{~nm}^{-3}$ and for temperatures lying between the room temperature and the nuclear fuel melting point.

The parameters of the EOS were determined using MD simulations results. The MD calculations, carried out in a wide $\rho-x-T$ range on unconfined and confined $\mathrm{Xe} / \mathrm{Kr}$ mixtures, were performed using accurate semi empirical potentials that were validated against quantum DFT results and experimental data.

It was shown in the present study that there is practically no matrix confinement effect on the noble gases. Therefore, the confinement parameter $\Delta R$ that appears in the EOS can be neglected $(\Delta R=0 \AA)$, that is, the EOS corresponding to the free noble gas mixtures can be safely used to describe the confined ones, irrespective of the type of confining fuel matrix $\left(\mathrm{UO}_{2}, \mathrm{PuO}_{2}\right.$ or $\left.\mathrm{MOX}\right)$

Because of its simple form, the EOS proposed here could be easily implemented in the nuclear fuel performance codes. Moreover, this new equation allows overcoming the drawbacks of the existing EOSs which cannot be used to describe $\mathrm{Xe} / \mathrm{Kr}$ mixtures and fail to characterize the noble gases at densities similar to those found in the intragranular bubbles $(>$ $\left.10 \mathrm{~nm}^{-3}\right)$ 


\section{Acknowledgments}

The calculations presented in the article were performed using the HPC resources of TGCC, the very large computing center of the French Atomic Energy Commission (CEA).

\section{Data availability}

The raw/processed data required to reproduce these findings are available from the corresponding author upon request. 


\section{References}

[1] J. Rest, An analytical study of gas-bubble nucleation mechanisms in uranium-alloy nuclear fuel at high temperature, J. Nucl. Mater. 402 (2010) 179-185.

[2] M. Tonks, D. Andersson, R. Devanathan, R. Dubourg, A. El-Azab, M. Freyss, F. Igleisas, K. Kulacsy, G. Pastore, S.R. Phillpot, M. Welland, Unit mechanisms of fission gas release: Current understanding and future needs, J. Nucl. Mater. 504 (2018) 300-317.

[3] P. Lösönen, On the behaviour of intragranular fission gas in $\mathrm{UO}_{2}$ fuel, J. Nucl. Mater. 280 (2000) 56-72.

[4] S. Kashibe, K. Une, K. Nogita, Formation and growth of intragranular fission gas bubbles in $\mathrm{UO}_{2}$ fuels with burnup of 6-83 GWd/t, J. Nucl. Mater. 206 (1993) 22-34.

[5] J. Noirot, L. Noirot, L. Desgranges, J. Lamontagne, Th. Blay, B. Pasquet, E. Muller, Fission Gas Inventory in PWR High Burnup Fuel: Experimental Characterization and Modeling, Proceedings of the International Meeting on LWR Fuel Performance, Orlando, USA Fl. 2004, Paper 1019, 329-338.

[6] M. Mogensen, C. Bagger, C.T. Walker, An experimental study of the distribution of retained xenon in transient-tested $\mathrm{UO}_{2}$ fuel, J. Nucl. Mater. 199 (1993) 85-101.

[7] K. Nogita, K. Une, High resolution TEM observation and density estimation of Xe bubbles in high burnup $\mathrm{UO}_{2}$ fuels, Nucl. Instrum. Meth. B 141 (1998) 481-486.

[8] D.R. Olander, D. Wongsawaeng, Re-solution of fission gas - A review: Part I. Intragranular bubbles, J. Nucl. Mater. 354 (2006) 94-109. 
[9] M.S. Veshchunov, On the theory of fission gas bubble evolution in irradiated $\mathrm{UO}_{2}$ fuel, $\mathbf{J}$. Nucl. Mater. 277 (2000) 67-81.

[10] I.R. Brearley, D.A. MacInnes, An improved equation of state for inert gases at high pressures, J. Nucl. Mater. 95 (1980) 239-252.

[11] C. Ronchi, Extrapolated equation of state for rare gases at high temperatures and densities, J. Nucl. Mater. 96 (1981) 314-328.

[12] A.B. Kaplun, A.B. Meshalkin, Thermodynamic Validation of the Form of Unified Equation of State for Liquid and Gas, High Temperature 41 (2003) 319-326.

[13] A.N. Zisman, I.V. Aleksandrov, S.M. Stishov, X-ray study of equations of state of solid xenon and cesium iodide at pressures up to 55 GPa, Phys. Rev. B 32 (1985) 484-487.

[14] A. Jelea, R.J.-M. Pellenq, F. Ribeiro, An atomistic modeling of the xenon bubble behavior in the $\mathrm{UO}_{2}$ matrix, J. Nucl. Mater. 444 (2014) 153-160.

[15] A.R. Leach, Molecular Modelling Principles and Applications, Pearson Education Limited, Harlow, 2001.

[16] D. Frenkel, B. Smit, Understanding Molecular Simulation, Academic Press, 2001.

[17] S. Plimpton, Fast Parallel Algorithms for Short-Range Molecular Dynamics, J. Comput. Phys. 117 (1995) 1-19.

[18] A.B. Belonoshko, R. Ahuja, B. Johansson, Molecular Dynamics Study of Melting and fcc-bcc Transitions in Xe, Phys. Rev. Lett. 87 (2001) 165505: 1-4.

[19] A.B. Belonoshko, Triple fcc-bcc-liquid point on the Xe phase diagram determined by the N-phase method, Phys. Rev. B 78 (2008) 174109: 1-7. 
[20] M.W.D. Cooper, M.J.D. Rushton, R.W. Grimes, A many-body potential approach to modelling the thermomechanical properties of actinide oxides, J. Phys.: Condens. Mat. 26 (2014) 105401: 1-10

[21] M.W.D. Cooper, S.T. Murphy, M.J.D. Rushton, R.W. Grimes, Thermophysical properties and oxygen transport in the $\left(\mathrm{U}_{\mathrm{x}} \mathrm{Pu}_{1-\mathrm{x}}\right) \mathrm{O}_{2}$ lattice, J. Nucl. Mater. 461 (2015) 206214.

[22] M.W.D. Cooper, N. Kuganathan, P.A. Burr, M.J.D. Rushton, R.W. Grimes, C.R. Stanek, D.A. Andersson, Development of $\mathrm{Xe}$ and $\mathrm{Kr}$ empirical potentials for $\mathrm{CeO}_{2}, \mathrm{ThO}_{2}, \mathrm{UO}_{2}$ and $\mathrm{PuO}_{2}$, combining DFT with high temperature MD, J. Phys.: Condens. Mat. 28 (2016) 405401 : $1-8$.

[23] M. Ross, M.H. Ree, Repulsive forces of simple molecules and mixtures at high density and temperature, J. Chem. Phys. 73 (1980) 6146-6152.

[24] M. Ross, A.K. McMahan, Condensed xenon at high pressure, Phys. Rev. B 21 (1980) $1658-1664$.

[25] C.L. Kong, M.R. Chakrabarty, Combining Rules for Intermolecular Potential Parameters. III. Application to the Exp 6 Potential, J. Phys. Chem. 77 (1973) 2668-2670.

[26] O. Sifner, J. Klomfar, Thermodynamic Properties of Xenon from the Triple Point to 800 K with Pressures up to $350 \mathrm{MPa}$, J. Phys. Chem. Ref. Data 23 (1994) 63-152.

[27] S.A. Ulybin, E.E. Ustyuzhanin, Thermodynamic properties of krypton, TVT 19 (1981) $279-286$

[28] A. Polian, J.M. Besson, M. Grimsditch, W.A. Grosshans, Solid krypton: Equation of state and elastic properties, Phys. Rev. B 39 (1989) 1332-1336. 
[29] R. Hellmann, B. Jäger, E. Bich, State-of-the-art ab initio potential energy curve for the xenon atom pair and related spectroscopic and thermophysical properties, J. Chem. Phys. 147 (2017) 034304: 1-10

[30] B. Jäger, R. Hellmann, E. Bich, E. Vogel, State-of-the-art ab initio potential energy curve for the krypton atom pair and thermophysical properties of dilute krypton gas, J. Chem. Phys. 144 (2016) 114304: 1-21.

[31] A. Jelea, Molecular dynamics modeling of helium bubbles in austenitic steels, Nucl. Instrum. Meth. B 425 (2018) 50-54.

[32] A.G.M. Ferreira, L.Q. Lobo, The fusion curves of xenon, krypton, and argon, J. Chem. Thermodyn. 40 (2008) 618-624.

[33] D. Errandonea, B. Schwager, R. Boehler, M. Ross, Phase behavior of krypton and xenon to $50 \mathrm{GPa}$, Phys. Rev. B 65 (2002) 214110: 1-6.

[34] M. Gottschalk, Equations of State for Complex Fluids, Rev. Mineral. Geochem. 65 (2007) 49-97.

[35] H. Flyvbjerg, H.G. Petersen, Error estimates on averages of correlated data, J. Chem. Phys. 91 (1989) 461-466. 


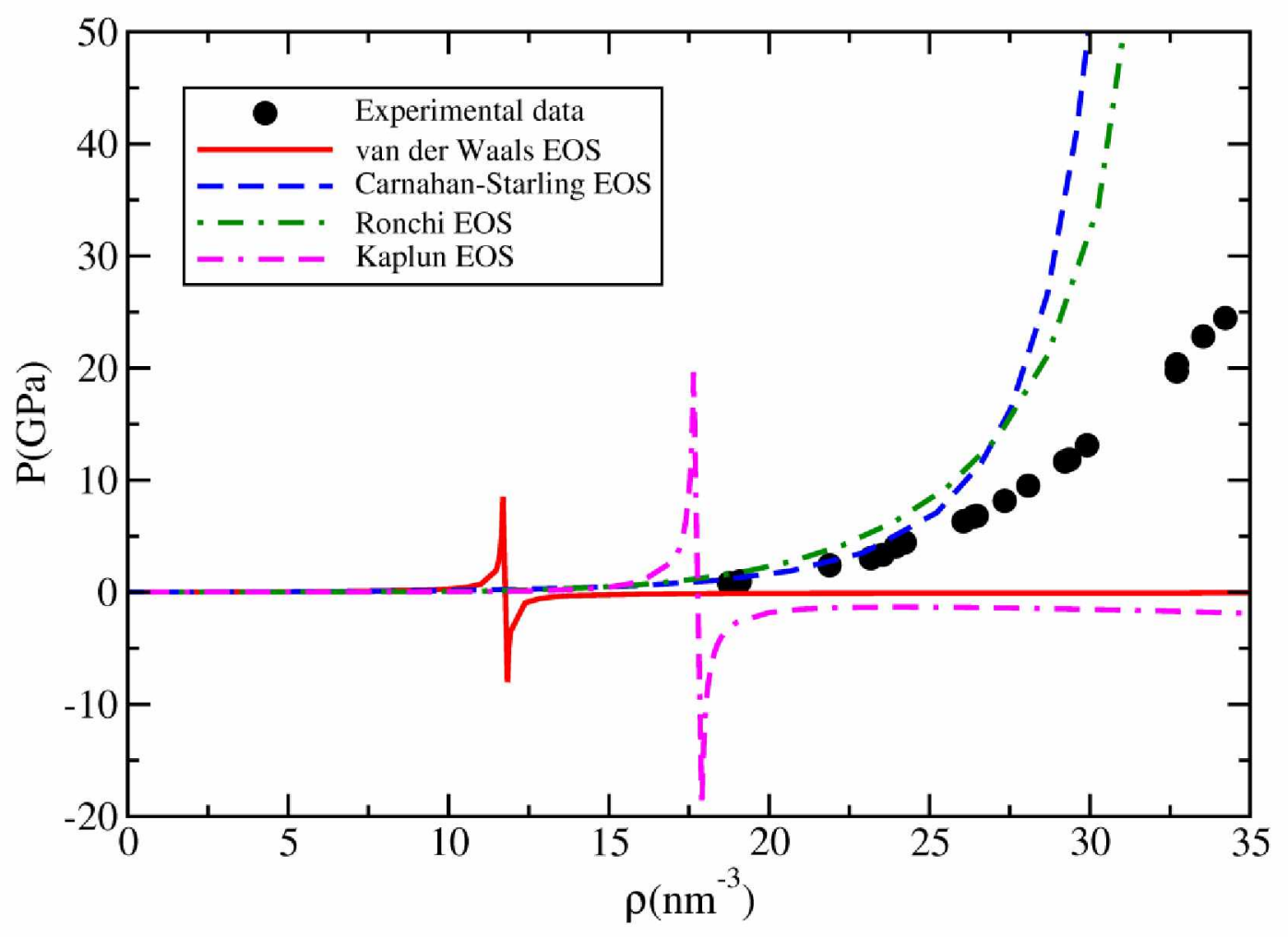

Fig. 1 


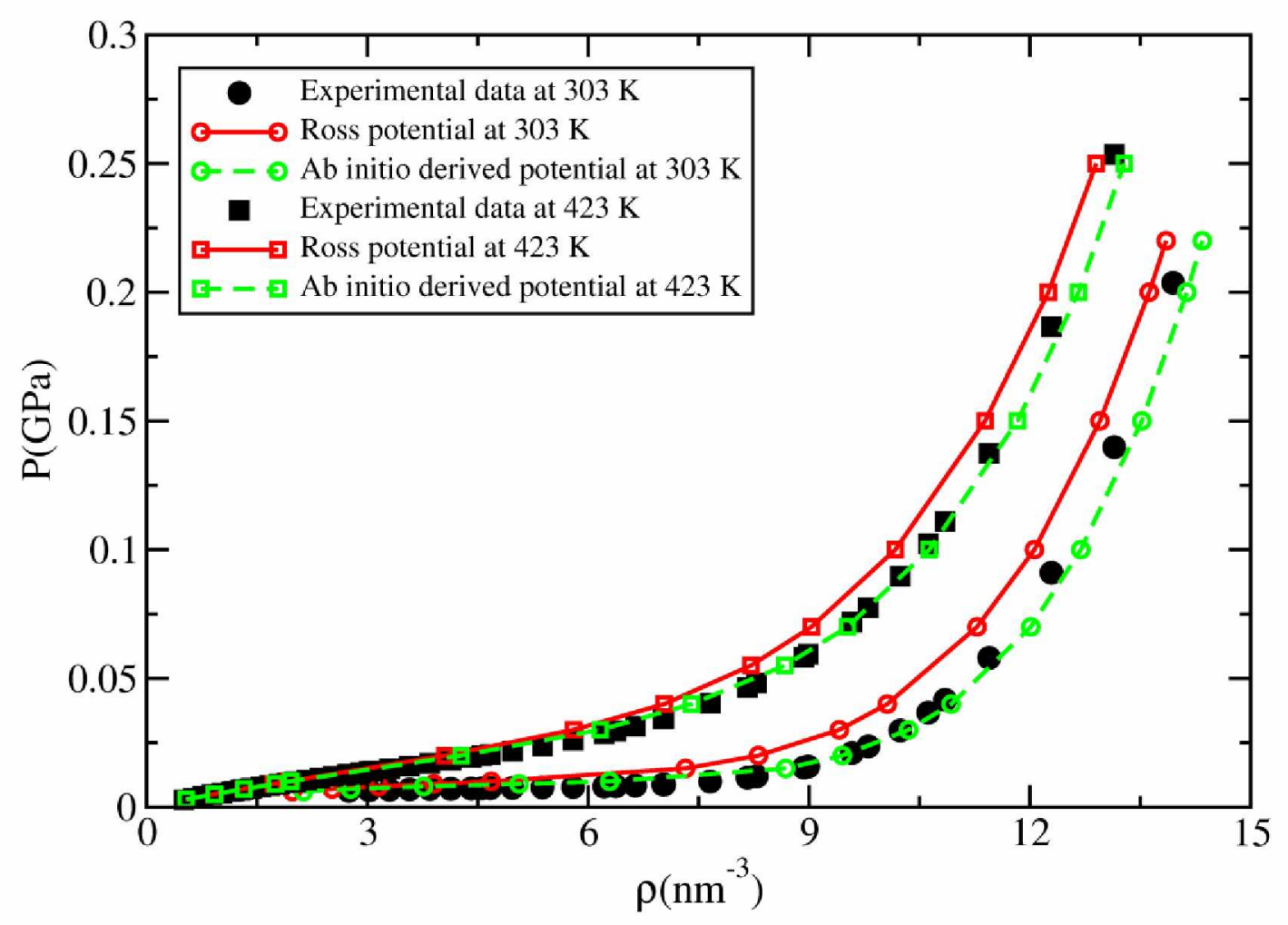

Fig. 2 


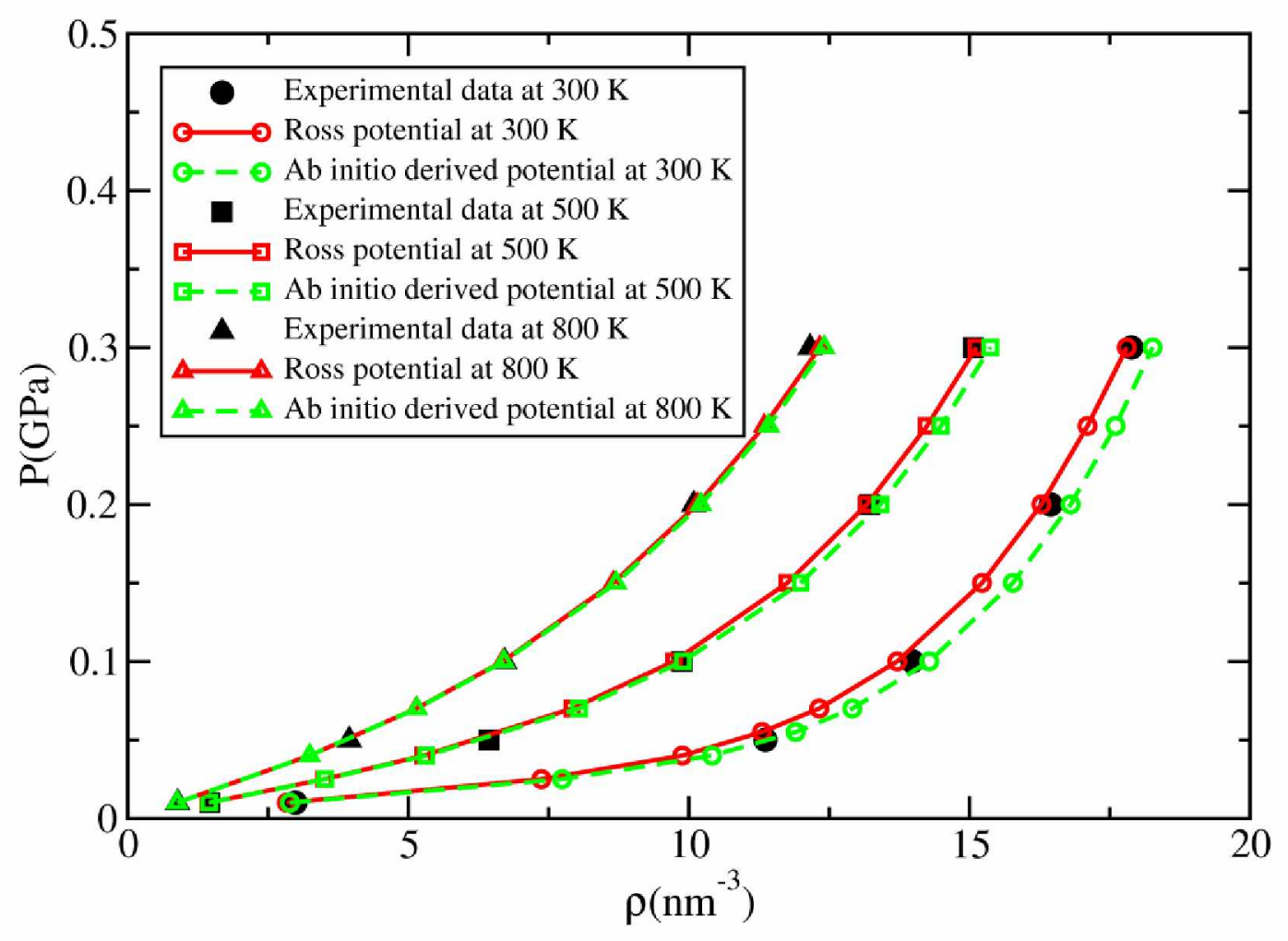

Fig. 3 


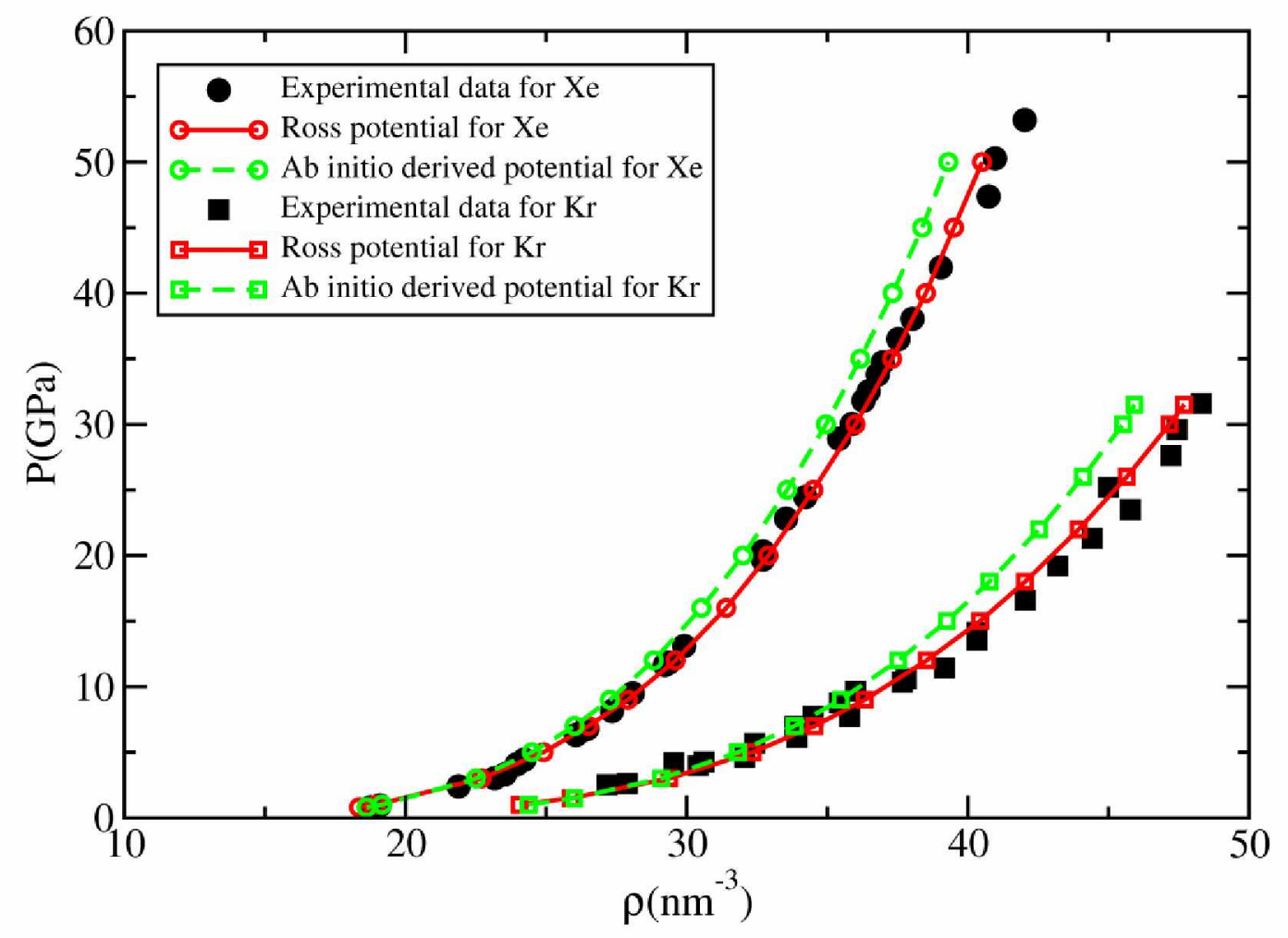

Fig. 4 

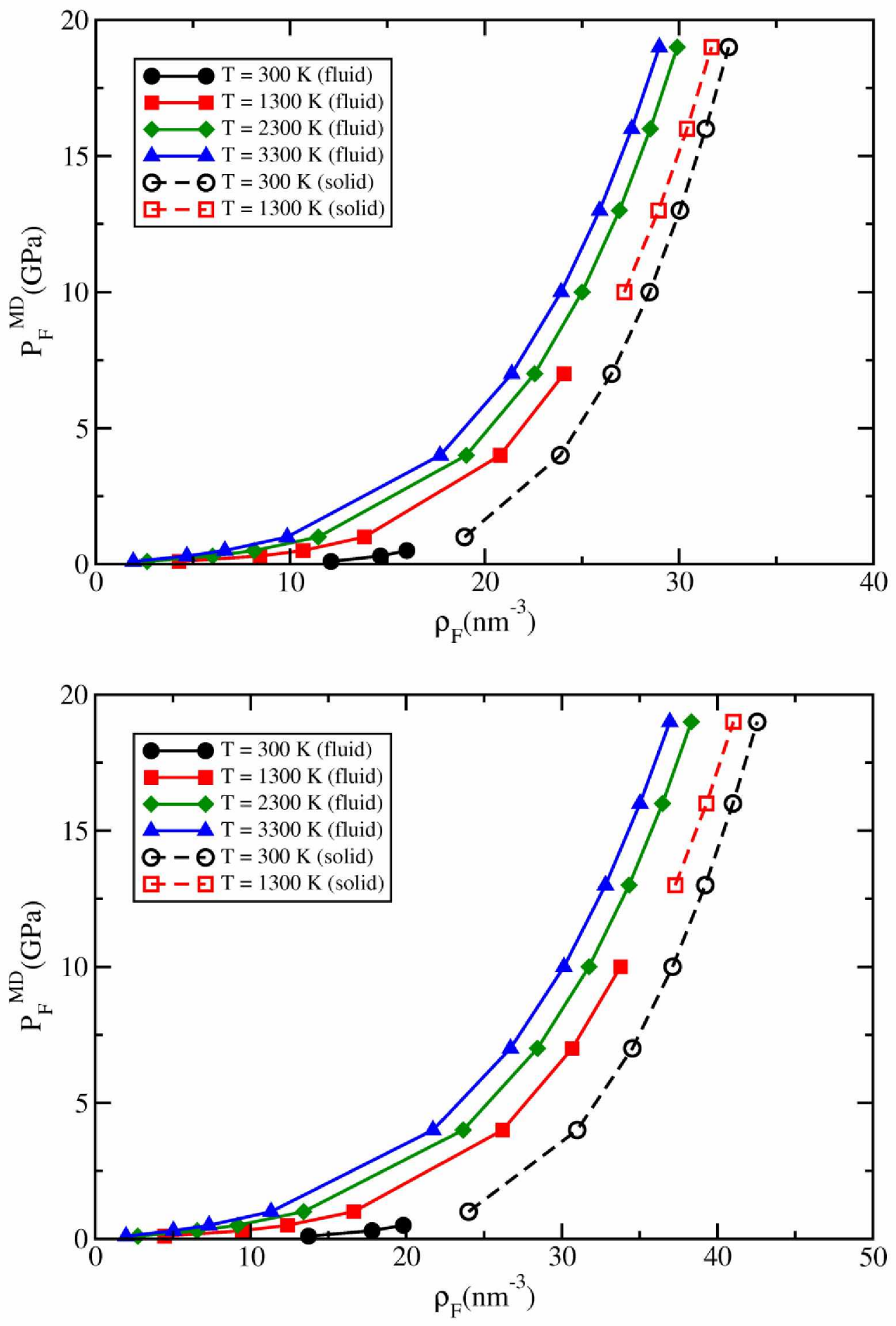

Fig. 5 


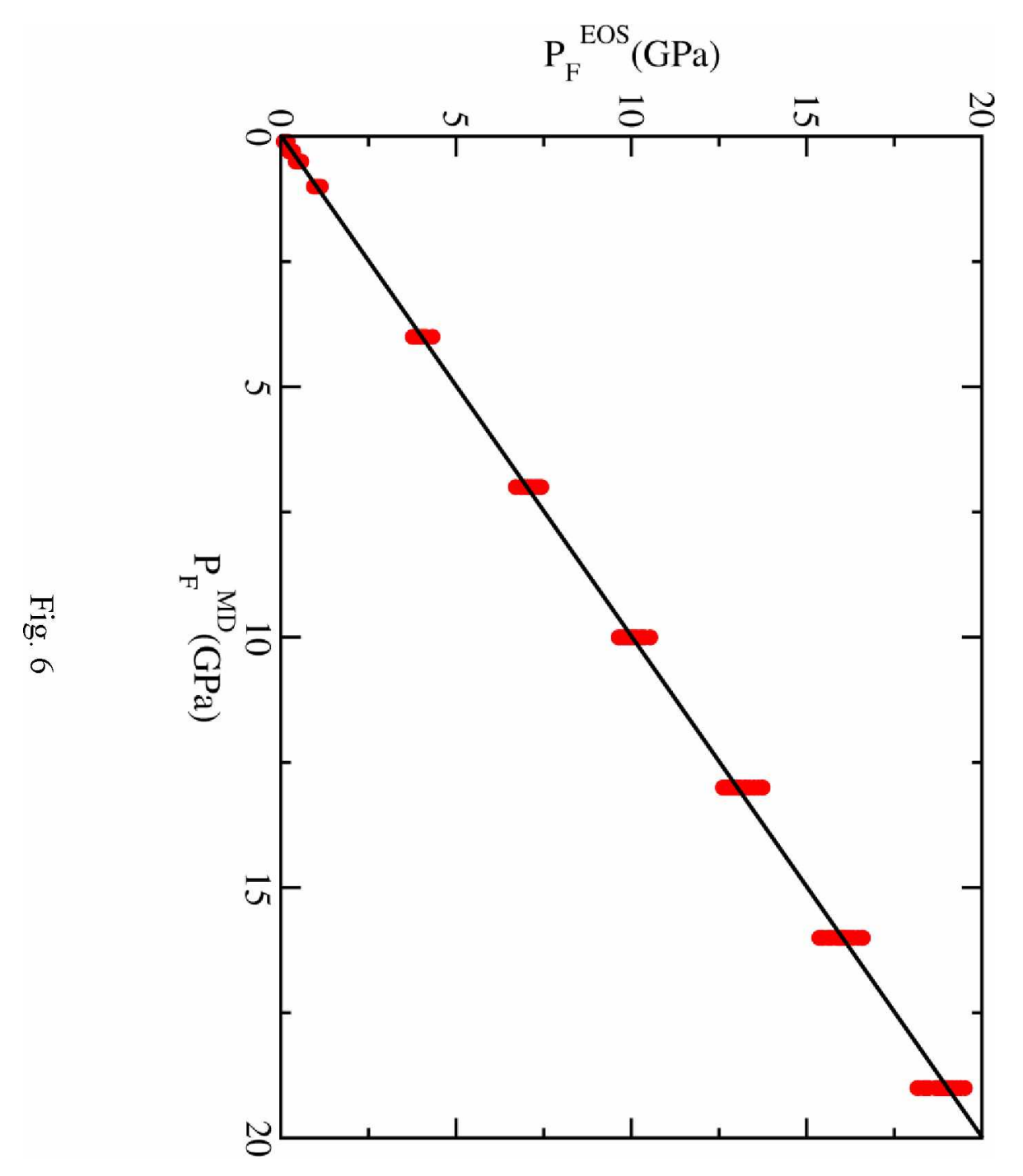




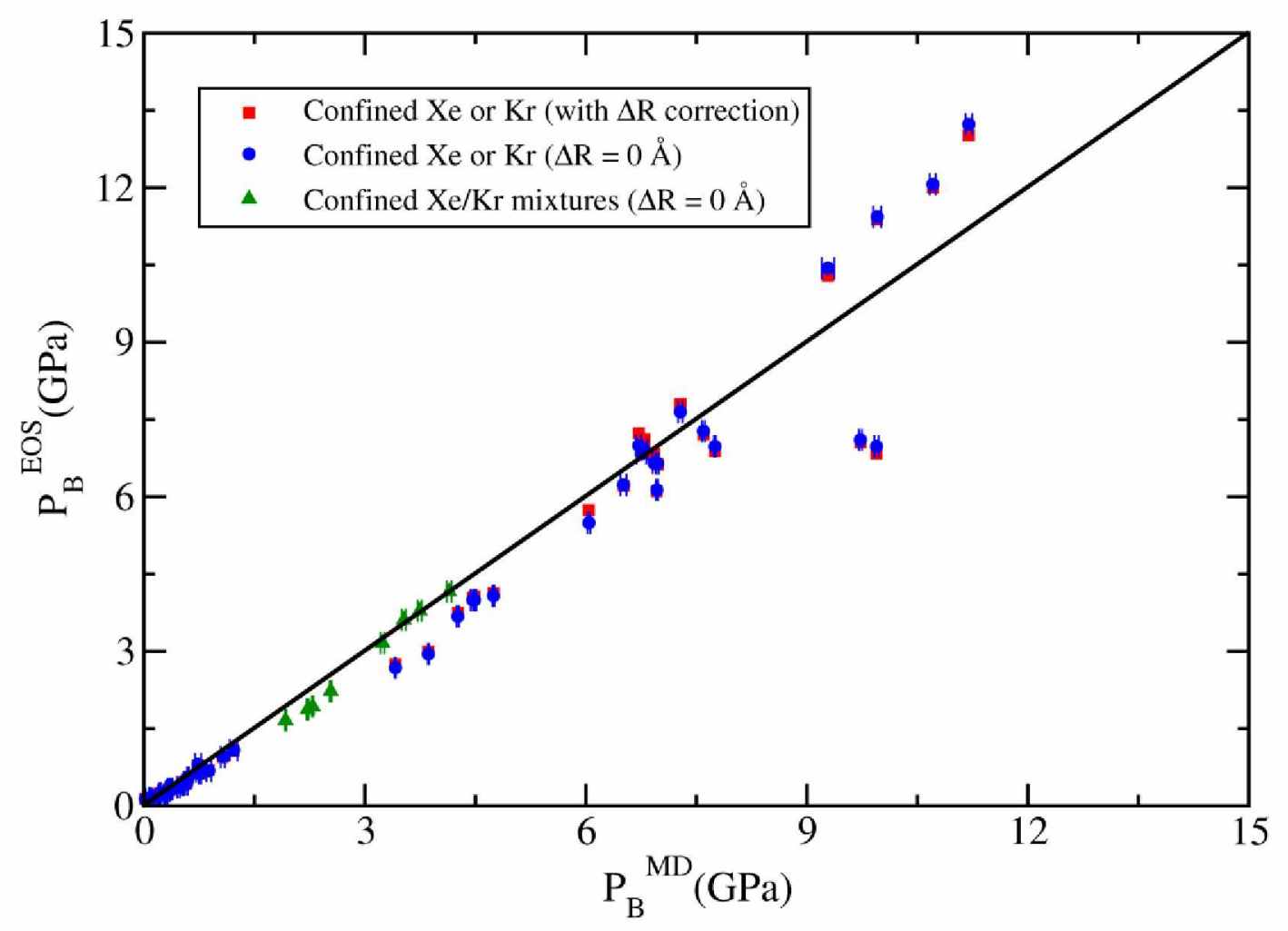

Fig. 7 


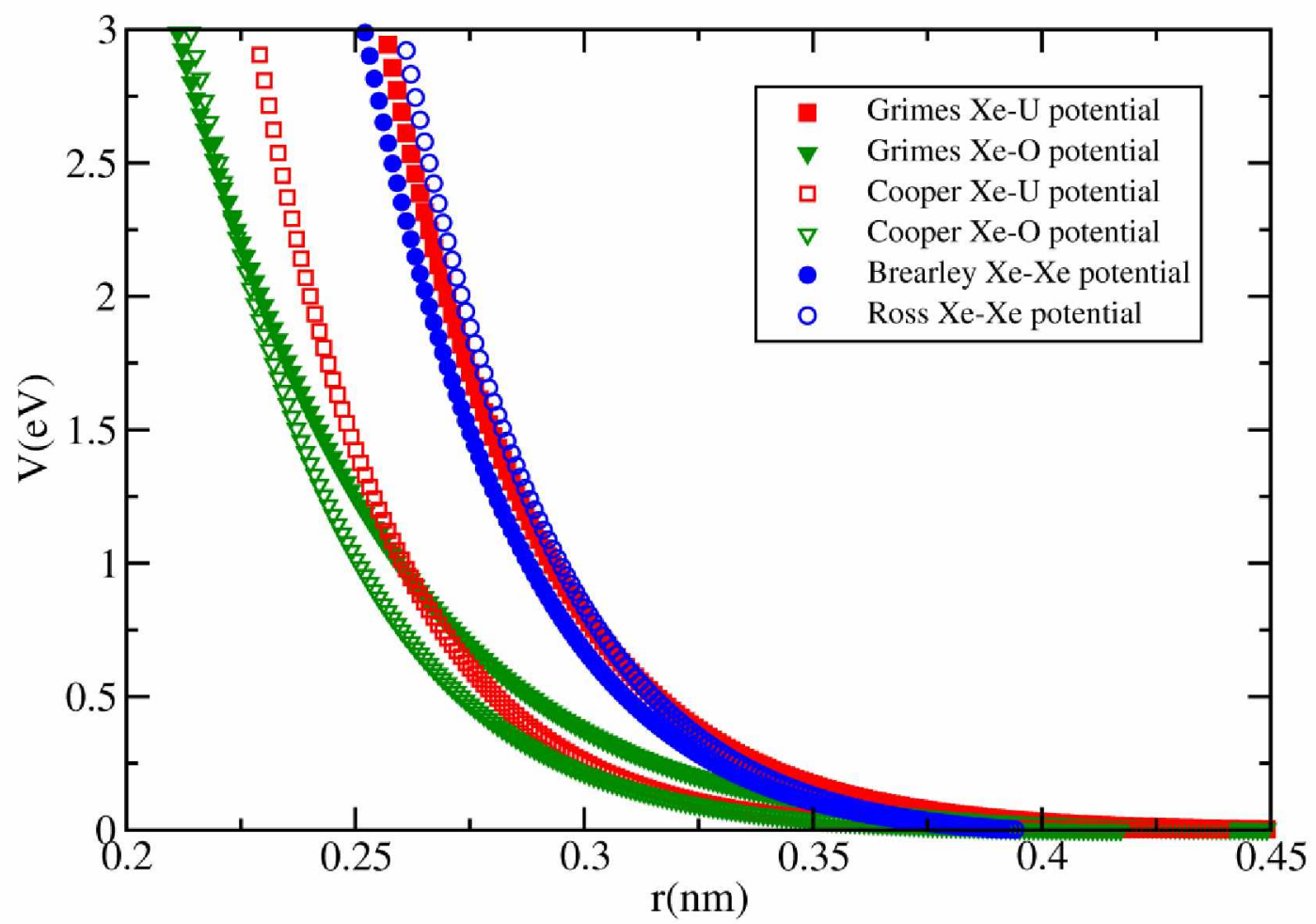

Fig. 8 


\section{Figure captions}

Fig. 1. Comparison between the $P(\rho)$ curves for Xe at $298 \mathrm{~K}$ calculated using the van der Waals, Carnahan-Starling [10], Ronchi [11] and Kaplun [12] EOSs and high density/pressure experimental data from reference [13].

Fig. 2. Comparison between the $P(\rho)$ curves for Xe at low densities/pressures calculated using the Ross and ab initio derived potentials and experimental data.

Fig. 3. Comparison between the $P(\rho)$ curves for $\mathrm{Kr}$ at low densities/pressures calculated using the Ross and ab initio derived potentials and experimental data.

Fig. 4. Comparison between the $P(\rho)$ curves for $\mathrm{Xe}$ and $\mathrm{Kr}$ at high densities/pressures calculated at $298 \mathrm{~K}$ using the Ross and ab initio derived potentials and experimental data.

Fig. 5. Sets of pressure-density MD data points (linked through eye-guiding lines) corresponding to pure unconfined $\mathrm{Xe}$ (top) and $\mathrm{Kr}$ (bottom).

Fig. 6. Comparison between the unconfined noble gas pressures calculated using the equation (8) and the corresponding MD results used in the fitting process.

Fig. 7. Comparison between the pressures of the confined noble gases (in a pure form or as a mixture) calculated using the EOS (equations (4)-(7)) either taking into account the confinement or not taking it into account $(\Delta R=0 \AA)$ and the corresponding MD mean pressures. The error bars represent the standard error of the MD mean pressures calculated using the "blocking method" $[16,35]$.

Fig. 8. Comparison between the Xe-matrix (Xe-U and Xe-O) and Xe-Xe potentials of Grimes and Brearley used in reference [14] and the corresponding ones of Cooper and Ross employed in the present study. 


\section{Table 1}

Parameters for the Born-Mayer functions used in the present work in the short distance region of the gas-matrix and gas-gas potentials.

\begin{tabular}{cccc}
\hline$a-b$ atom pair & $B_{a b}(\mathrm{eV})$ & $D_{a b}(\AA)$ & $r_{c u t}(\AA)$ \\
\hline $\mathrm{Xe}-\mathrm{U}$ & 2815.17 & 0.3989 & 0.791 \\
$\mathrm{Xe}-\mathrm{Pu}$ & 2648.98 & 0.3864 & 0.787 \\
$\mathrm{Xe}-\mathrm{O}$ & 480.81 & 0.4807 & 1.188 \\
$\mathrm{Kr}-\mathrm{U}$ & 3483.58 & 0.3796 & 0.756 \\
$\mathrm{Kr}-\mathrm{Pu}$ & 3290.25 & 0.3669 & 0.753 \\
$\mathrm{Kr}-\mathrm{O}$ & 435.73 & 0.4604 & 1.170 \\
$\mathrm{Xe}-\mathrm{Xe}$ & 1579.76 & 0.4929 & 1.314 \\
$\mathrm{Kr}-\mathrm{Kr}$ & 1137.85 & 0.4528 & 1.207 \\
$\mathrm{Xe}-\mathrm{Kr}$ & 1359.39 & 0.4726 & 1.257 \\
\hline
\end{tabular}




\section{Table 2}

Parameters for the exp- 6 potentials used to describe the gas-gas interactions.

\begin{tabular}{cccc}
\hline$a-b$ atom pair & $\varepsilon_{a b}(\mathrm{eV})$ & $r^{*}{ }_{a b}(\AA)$ & $\alpha_{a b}$ \\
\hline $\mathrm{Xe}-\mathrm{Xe}$ & 0.02025073 & 4.470 & 13.000 \\
$\mathrm{Kr}-\mathrm{Kr}$ & 0.01458914 & 4.106 & 13.000 \\
$\mathrm{Xe}-\mathrm{Kr}$ & 0.01693305 & 4.296 & 13.025 \\
\hline
\end{tabular}




\section{Table 3}

Comparison between the trapping energies $E_{T}$ in electronvolts for $\mathrm{Xe}$ and $\mathrm{Kr}$ at different sites of a $7 \times 7 \times 7 \mathrm{UO}_{2}$ or $\mathrm{PuO}_{2}$ supercell calculated with our set of potentials and the corresponding values (given in brackets) from Fig. 4 of reference [22]. The trapping sites into the actinide oxides matrices are: oxygen vacancies $O V$, actinide vacancies $A c V$ and the three configurations of the Shottky defects $S D 1, S D 2$ and $S D 3$, as defined in reference [22].

\begin{tabular}{cccl}
\hline Noble gas atom/Matrix & $E_{T}{ }^{O V}$ & $E_{T}{ }^{A c V}$ & $E_{T}^{S D 1} / E_{T}^{S D 2} / E_{T}^{S D 3}$ \\
\hline $\mathrm{Xe} / \mathrm{UO}_{2}$ & $-3.4(-3.4)$ & $-8.1(-8.0)$ & $-9.7 /-8.7 /-8.2(-8.7)$ \\
$\mathrm{Kr} / \mathrm{UO}_{2}$ & $-2.2(-2.3)$ & $-6.2(-6.4)$ & $-7.3 /-6.4 /-6.2(-6.4)$ \\
$\mathrm{Xe} / \mathrm{PuO}_{2}$ & $-3.6(-3.5)$ & $-7.7(-7.5)$ & $-9.6 /-8.4 /-7.9(-8.5)$ \\
$\mathrm{Kr} / \mathrm{PuO}_{2}$ & $-2.4(-2.3)$ & $-5.8(-5.8)$ & $-7.1 /-6.2 /-5.9(-6.0)$ \\
\hline
\end{tabular}




\section{Table 4}

Comparison between the values of the bubble radii $\left(R_{B}\right)$, densities $\left(\rho_{B}\right)$ and pressures $\left(P_{B}\right)$ in the bubble for the largest dense bubbles analyzed in the present study placed in $7 \times 7 \times 7$ $\mathrm{UO}_{2} / \mathrm{PuO}_{2}$ supercells and the corresponding values (given in brackets) for bubbles placed in larger $9 \times 9 \times 9$ supercells.

\begin{tabular}{cccc}
\hline Noble gas atom/Matrix & $R_{B}(\mathrm{~nm})$ & $\rho_{B}\left(\mathrm{~nm}^{-3}\right)$ & $P_{B}(\mathrm{GPa})$ \\
\hline $\mathrm{Xe} / \mathrm{UO}_{2}$ & $1.18(1.18)$ & $23.8(24.0)$ & $6.97(7.22)$ \\
$\mathrm{Kr} / \mathrm{UO}_{2}$ & $1.16(1.16)$ & $25.2(25.1)$ & $4.26(4.27)$ \\
$\mathrm{Xe} / \mathrm{PuO}_{2}$ & $1.17(1.16)$ & $24.4(25.3)$ & $7.59(8.14)$ \\
$\mathrm{Kr} / \mathrm{PuO}_{2}$ & $1.15(1.15)$ & $26.0(25.8)$ & $4.74(4.72)$ \\
\hline
\end{tabular}




\section{Table 5}

Parameters $A_{i j}, B_{i j}, C_{i j}$ to be used in the EOS. In this equation, one employed the following units: the GPa for the pressure, the Kelvin for the temperature, the angstrom $\AA$ ( $1 \AA=10^{-1}$ $\mathrm{nm})$ for $R_{B}$ and $\Delta R$ and the $\AA^{-3}\left(1 \AA^{-3}=1000 \mathrm{~nm}^{-3}\right)$ for the density. Within this system of units, the Boltzmann's constant takes the value $k=1.38066 \times 10^{-2} \mathrm{GPa} \cdot \AA^{3} \cdot \mathrm{K}^{-1}$.

\begin{tabular}{cccc}
\hline$i j$ & $A_{i j}$ & $B_{i j}$ & $C_{i j}$ \\
\hline 11 & $-1.141 \times 10^{-3}$ & $1.211 \times 10^{-3}$ & $2.263 \times 10^{-3}$ \\
12 & $3.653 \times 10^{0}$ & $-3.100 \times 10^{0}$ & $-8.204 \times 10^{0}$ \\
13 & $-1.281 \times 10^{3}$ & $-6.951 \times 10^{2}$ & $7.422 \times 10^{3}$ \\
21 & $4.523 \times 10^{-2}$ & $6.177 \times 10^{-2}$ & $-3.123 \times 10^{-1}$ \\
22 & $-7.717 \times 10^{1}$ & $-4.800 \times 10^{2}$ & $1.348 \times 10^{3}$ \\
23 & $-9.698 \times 10^{4}$ & $7.368 \times 10^{5}$ & $-1.221 \times 10^{6}$ \\
31 & $9.027 \times 10^{-1}$ & $-5.386 \times 10^{0}$ & $8.211 \times 10^{0}$ \\
32 & $-5.182 \times 10^{3}$ & $2.498 \times 10^{4}$ & $-3.368 \times 10^{4}$ \\
33 & $1.020 \times 10^{7}$ & $-4.138 \times 10^{7}$ & $4.740 \times 10^{7}$ \\
\hline
\end{tabular}

